\title{
Complicação pós-cirúrgica de enxerto ósseo em mandíbula pós-ressecção de ameloblastoma: a importância da colaboração do paciente
}

\author{
Post-surgical complication of bone graft in the mandible post-recovery of \\ ameloblastoma: the importance of patient collaboration \\ Complicación post-quirúrgica de injerto óseo en mandíbula después de la \\ resección de ameloblastoma: la importancia de la colaboración del paciente \\ Salmo CORTIGLIO ${ }^{1}$ \\ Bruna da Fonseca WASTNER ${ }^{1}$ \\ Joana Letícia VENDRUSCOLO ${ }^{2}$ \\ Flavia Hinterholz LAUSCHNER ${ }^{3}$ \\ José Luis DISSENHA ${ }^{1,4}$ \\ ${ }^{1}$ Hospital Erasto Gartner 81520-060, Curitiba-PR, Brasil \\ ${ }^{2}$ Graduação em Odontologia, Universidade Federal do Paraná (UFPR) 80210-170, Curitiba-PR, Brasil \\ ${ }^{3}$ Cirurgiã-Dentista, Universidade da Região de Joinville - UNIVILLE 89219-71, Joinville-SC, Brasil \\ ${ }^{4}$ Hospital Maternidade Municipal São José dos Pinhais
}

\section{Resumo}

O ameloblastoma é um tumor local invasivo que se origina do remanescente da lâmina dentinária e do epitélio odontogênico. O objetivo deste trabalho é apresentar um caso de ameloblastoma multicistico tratado com ressecção óssea ampla e reconstrução imediata que sofreu complicações pós-operatórias. Paciente do sexo masculino, 32 anos, foi atendido no Pronto-Socorro do Hospital e Maternidade do Município de São José dos Pinhais - PR relatando parestesia na região de mandíbula direita. No exame físico, observou-se tumefação indolor na região dos molares de coloração similar aos tecidos adjacentes. A radiografia panorâmica mostrava lesão radiolúcida multilocular em mandíbula direita, com aproximadamente 4 centímetros de diâmetro. Foi realizada biópsia incisional e o exame histopatológico foi compatível com ameloblastoma multicistico. O tratamento definitivo proposto foi ressecção ampla e reconstrução com enxerto de crista ilíaca. Após 60 dias, o paciente voltou relatando dor e edema na área operada. Na radiografia panorâmica observou-se deslocamento do enxerto no coto e do material de osteossíntese. Paciente informou ter sido preso nesse período e negligenciado os cuidados pós-operatórios. Foi programada nova intervenção cirúrgica. O enxerto não foi fixado novamente devido contaminação da região. O mesmo retornou após 1 semana sem os elásticos e referiu que não irá realizar o tratamento proposto. Cirurgias radicais geralmente acarretam aos pacientes sérias complicações. Entretanto, o ameloblastoma tem alta incidência de recidiva quando não removido adequadamente, tornando a ressecção cirúrgica do tumor, o tratamento de escolha para esse tipo de lesão. Porém, a adesão do paciente ao tratamento proposto é fator decisivo para controle efetivo da lesão e para a boa evolução do quadro.

Descritores: Ameloblastoma; Unidade Hospitalar de Odontologia; Procedimentos Cirúrgicos Bucais.

\section{Abstract}

Ameloblastoma is invasive local tumor, that may arise from rests of the dental lamina and epithelial lining of a odontogenic cyst. The aim of this article is to present a case report of multicystic ameloblastoma treated with a broad bone resection followed by reconstruction that suffered postoperative complications. A 32-year-old male patient was treated at the Emergency Room of the Hospital and Maternity Hospital of the Municipality of São José dos Pinhais - PR, reporting paraesthesia in the right jaw region. At the physical examination, painless swelling was observed in the region of molars similar to adjacent tissues. The panoramic radiograph showed multilocular radiolucent lesion in the right mandible, approximately 4 centimetres in diameter. An incisional biopsy was performed and histopathological examination was compatible with multicystic ameloblastoma. The proposed definitive treatment was extensive resection and reconstruction with iliac crest graft. After 60 days, the patient returned to report pain and edema in the operated area. In the panoramic radiograph, graft displacement was observed in the stump and in the osteosynthesis material. Patient reported being arrested at this time and neglected post-operative care. Further surgery was scheduled. The graft was not fixed again due to contamination of the region. The same returned after 1 week without the rubber bands and said that it will not carry out the proposed treatment. Radical surgeries usually cause serious complications for patients. However, ameloblastoma has a high incidence of relapse when not adequately removed. Making surgical resection of the tumor is treatment of choice for this type of injury. However, the patient's adherence to the proposed treatment is a decisive factor for effective control of the lesion and for the good evolution of the condition.

Descriptors: Ameloblastoma; Dental Service, Hospital; Oral Surgical Procedures.

\section{Resumen}

El ameloblastoma es un tumor local invasivo que se origina del remanente de la lámina dentinaria y del epitelio odontogénico. El objetivo de este trabajo es presentar un caso de ameloblastoma multicistico tratado con resección ósea amplia y reconstrucción inmediata que sufrió complicaciones postoperatorias. Paciente del sexo masculino, 32 años, fue atendido en la sala de emergencias del hospital y Maternidad del municipio de São José dos Pinhais - PR, relata parestesia en la región de la mandíbula derecha. En el examen físico se observó unefato indoloro en la región de los molares de coloración similar a los tejidos adyacentes. La radiografía panorámica mostro radiolúcida multilocular en la mandíbula derecha, con aproximadamente $4 \mathrm{~cm}$ de diámetro. Fue realizada la biopsia incisional y el examen histopatológico fue compatible con ameloblastoma multicanal. El tratamiento definitivo propuesto fue resección amplia y reconstrucción con injerto de cresta ilíaca. Después de 60 días, el paciente regresó relatando dolor y edema en el área operada. En la radiografía panorámica se observó desplazamiento del injerto en el coto y del material de osteosíntesis. El paciente conto que fue preso durante ese periodo y no se tuvo cuidado en los cuidados post operatorios. Fue programada una nueve intervención quirúrgica. El injerto no se fijó nuevamente debido a la contaminación de la región. El paciente regresó después de 1 semana sin los elásticos y declaró que no iba a realizar el tratamiento propuesto. Las cirugías radicales generalmente generan al paciente serias complicaciones. Sin embargo, considerando las características del ameloblastoma de alta incidencia de recidiva si no se retira adecuadamente, la resección quirúrgica del tumor sigue siendo el tratamiento de elección para ese tipo de lesión. Sin embargo, la adhesión del paciente al tratamiento propuesto es factor decisivo para el control efectivo de la lesión y para la buena evolución del cuadro.

Descriptores: Ameloblastoma; Servicio Odontológico Hospitalario; Procedimientos Quirúrgicos Orales.

\section{INTRODUÇÃO}

O ameloblastoma é um tumor local invasivo que se origina do remanescente da lâmina dentinária e do epitélio odontogênico ${ }^{1}$, representando $1 \%$ dos tumores odontogênicos.

Os dados da literatura mostram uma prevalência de $20 \%$ em maxila, predominantemente na região de caninos e molares, e $80 \%$ na mandíbula, principalmente na região de molares e de ramo ascendente da mandíbula². O tumor é prejudicial aos tecidos adjacentes, com alta taxa de recorrência e possível alteração malignidade ${ }^{3}$. Os sinais/sintomas mais comuns são crescimento lento e sem dor que pode ocasionar deformidade facial, maloclusão, perda dentária, dor e parestesia na região afetada ${ }^{4}$. O tratamento consiste em cirurgia radical, que consiste em ressecção ampla da maxila ou mandíbula, podendo ser marginais, segmentares 
ou compostas. Tratamentos mais conservadores como curetagem, eletrocauterização, cirurgia e aplicação de agentes esclerosantes também são descritos na literatura ${ }^{5,6}$. O ameloblastoma pode apresentar-se de quatro maneiras: multicistico/sólido, unicístico, extraósseo e desmoplásico ${ }^{7}$. O ameloblastoma multicístico acomete normalmente adultos entre 30 e 70 anos, sem predileção de gênero e ocorre principalmente na região posterior da mandíbula ${ }^{8}$. Este tipo de ameloblastoma compreende aproximadamente $10 \%$ de todos os tumores odontogênicos de mandíbula ${ }^{9}$. Muitos estudos sugerem o tratamento como um importante fator no prognóstico da lesão, pois tratamentos conservadores podem implicar em recidiva do tumor $^{10}$. Sendo assim, o objetivo deste é apresentar um caso de ameloblastoma multicistico tratado com ressecção óssea ampla e reconstrução imediata e que sofreu complicações pós-operatórias.

\section{CASO CLÍNICO}

Paciente do sexo masculino, 32 anos, leucoderma, foi atendido no Pronto-Socorro do Hospital e Maternidade do Município de São José dos Pinhais - PR relatando parestesia na região de mandíbula direita. No exame físico observou-se tumefação indolor na região dos molares de coloração similar aos tecidos adjacentes. Radiografia panorâmica mostrava lesão radiolúcida multilocular em mandíbula direita, com aproximadamente $4 \mathrm{~cm}$ de diâmetro, envolvendo ângulo de mandíbula e com evidência de destruição basilar (Figura 1).

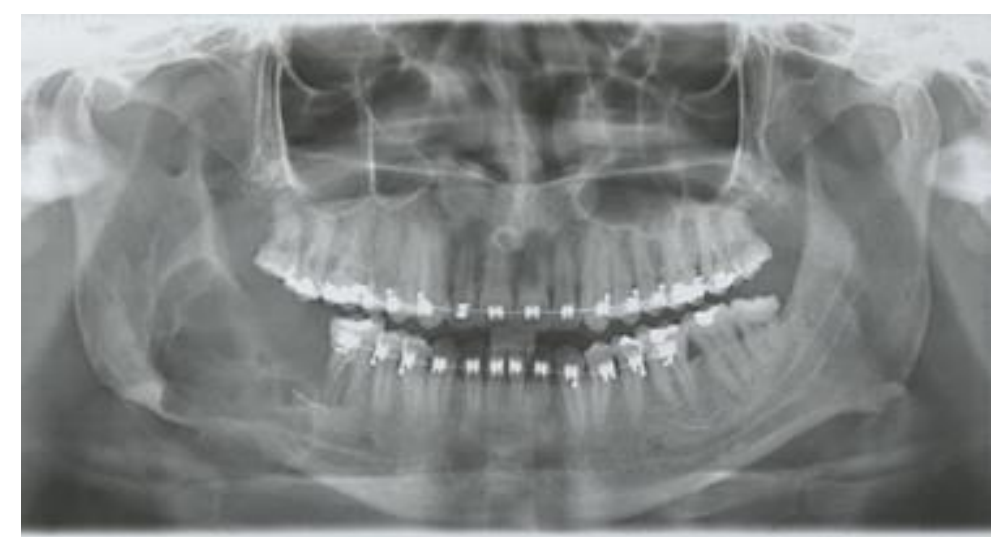

Figura 1: Radiografia panorâmica inicial mostrando lesão radiolúcida multilocular em mandíbula direita.

Foi realizada biópsia incisional sob anestesia local e o exame histopatológico foi compatível com ameloblastoma multicistico. O tratamento definitivo proposto foi ressecção ampla e reconstrução com enxerto de crista ilíaca. Foi realizado acesso extraoral submandibular, localizada a lesão e realizada mandibulectomia parcial desde o dente 45 até a região de ramo mandibular. $\mathrm{O}$ enxerto de crista ilíaca foi fixado no coto anterior com duas placas retas quatro furos se deu nos cotos anterior e posterior com duas placas retas de quatro furos em cada, sistema 2.0 (Figura 2).

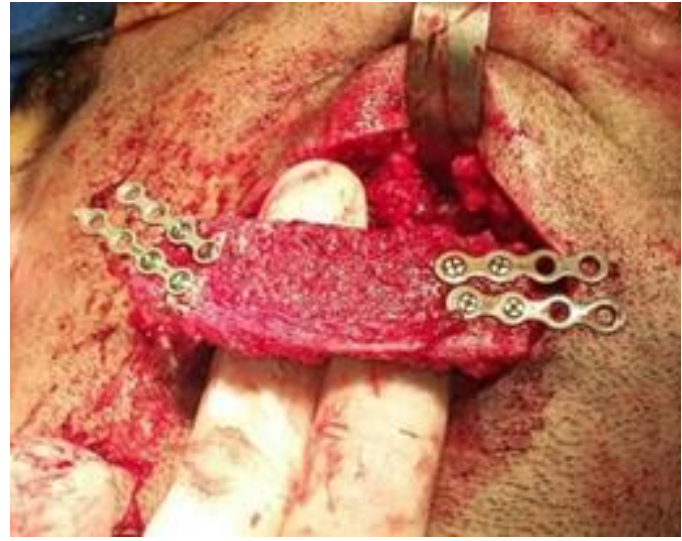

Figura 2: Transoperatório mostrando a fixação do enxerto.

O pós-operatório imediato transcorreu sem complicações e o paciente teve alta no dia seguinte ao procedimento. Após 60 dias, o paciente voltou relatando dor e edema na área operada. Na radiografia panorâmica observouse deslocamento do enxerto no coto e do material de osteossíntese (Figura 3).

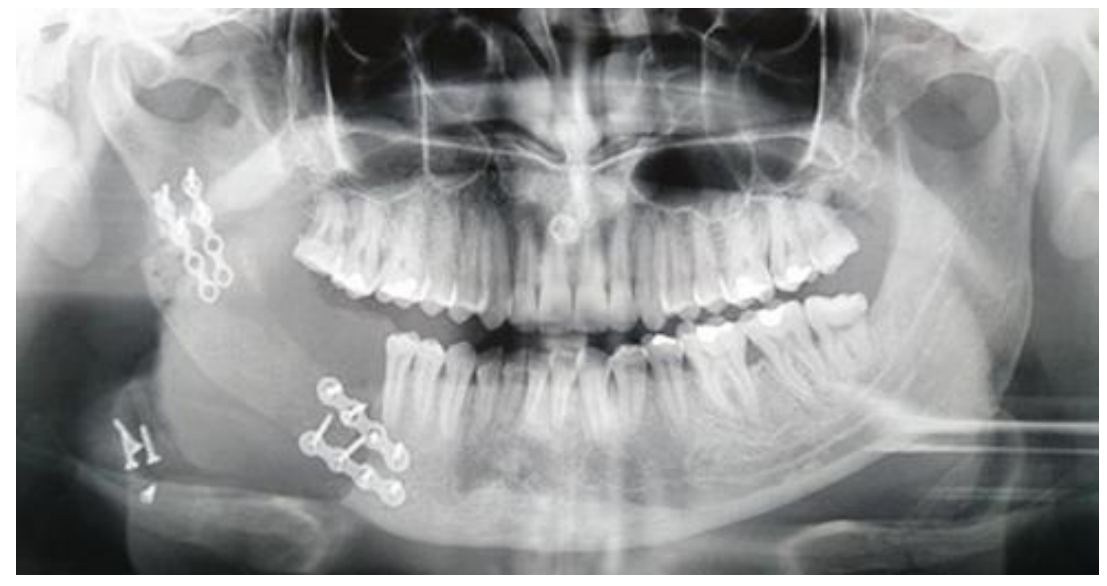

Figura 3: Radiografia panorâmica pós-operatória mostrando deslocamento do material de ostoessíntese.

O paciente informou ter sido cumprido pena em regime fechado nesse período e negligenciado os cuidados pós-operatórios. Assim foi programada nova intervenção cirúrgica para tratamento da complicação. $\mathrm{O}$ bloqueio mandíbulo-maxilar com barra de Erich foi realizado antes do início do procedimento para estabilizar a oclusão. $\mathrm{O}$ acesso à mandíbula se deu sobre a sobre a cicatriz da cirurgia anterior e, no momento da divulsão, houve drenagem de secreção purulenta em abundância. Então foram removidas as placas e parafusos do coto mandibular distal que estavam soltas. $\mathrm{O}$ enxerto não foi fixado novamente devido contaminação da região. $\mathrm{O}$ paciente foi liberado no dia seguinte e apresentou uma boa evolução. Porém, o paciente retornou após uma semana em consulta de retorno sem os elásticos, apresentando trismo, dificuldade mastigatória e infecção recorrente na região. O paciente relatou que não iria realizar o tratamento proposto. Radiografia panorâmica 30 dias após o segundo procedimento cirúrgico mostrou deslocamento e nãoconsolidação do enxerto na região proximal (Figura 4).

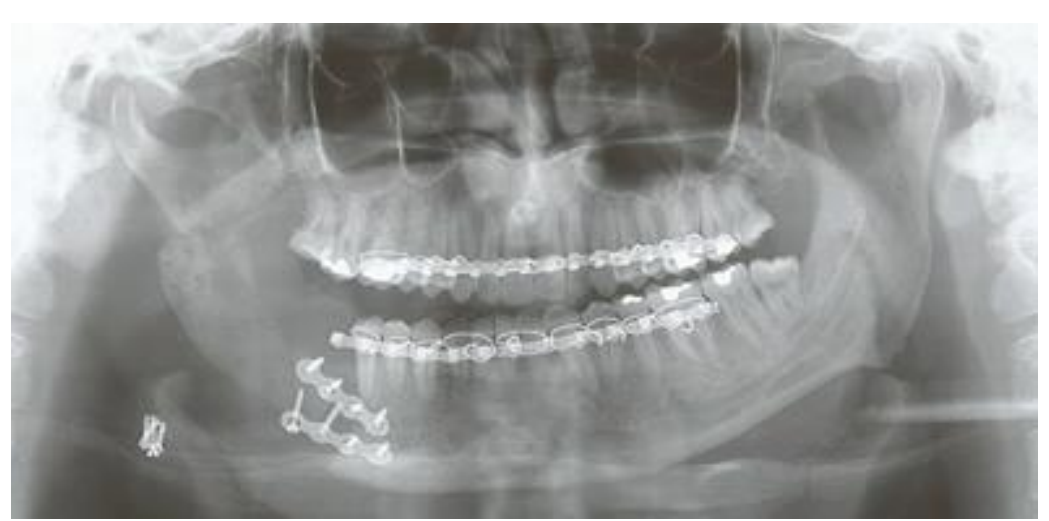

Figura 4: Radiografia panorâmica após a remoção do material de osteossíntese, mostrando deslocamento e não-consolidação do enxerto.

\section{DISCUSSÃO}

O ameloblastoma multicístico é um tumor benigno do epitélio odontogênico que ocorre mais frequentemente na mandíbula. A maioria dos casos é diagnosticada em adultos com idade média de 35 anos, sem predileção de gênero ${ }^{9}$, dados que estão de acordo com o paciente do caso, o qual apresentava lesão em região de mandíbula do lado direito, tendo 32 anos no momento do diagnóstico.

O procedimento cirúrgico é o principal tratamento para o ameloblastoma multicístico. A ressecção em bloco ampla é recomendada devido à alta taxa de recidiva deste tipo do tumor. O ameloblastoma multicístico apresenta de $13 \%$ a $15 \%$ de chance de recidiva após o tratamento com ressecção cirúrgica em bloco. Em contrapartida, caso seja realizada apenas curetagem do tumor, a chance de recidiva aumenta para $90-100 \%{ }^{10}$. Inúmeros autores recomendam uma margem de segurança de $1,5 \mathrm{~cm}$ a $2 \mathrm{~cm}$ além do limite radiográfico a fim de garantir que todos os microcistos sejam removidos ${ }^{11}$.

Cirurgias radicais geralmente acarretam ao paciente sérias complicações envolvendo deformidade facial, disfunção mastigatória e movimentação anormal da mandíbula. Entretanto, considerando as características do ameloblastoma de alta incidência de recidiva se não for 
adequadamente removido, a ressecção cirúrgica do tumor continua sendo o tratamento de escolha para esse tipo de lesão ${ }^{2}$.

Os retalhos ósseos vascularizados tem potencial de reconstrução de qualquer extensão ou defeito ósseo ${ }^{8}$. São aplicáveis em defeitos de maxila e mandíbula pois possuem boa cobertura tecidual e adequada vascularização no leito receptor, favorecendo a cicatrização, porém constitui um procedimento de alta complexidade e alto custo que envolve várias equipes cirúrgicas ${ }^{12}$. A escolha pela crista ilíaca se dá pela quantidade disponível e fácil acesso cirúrgico, necessitando de um médico ortopedista para remover o fragmento ósseo para a equipe odontológica ${ }^{13}$. As maiores causas de insucesso deste tipo de enxerto são o mau cuidado do paciente, a presença de fatores sistêmicos não compensados e a má fixação do fragmento pelo cirurgião bucomaxilofacial $^{14}$. O paciente deve evitar esforço físico no período de 30 dias, não deve fumar e manter alimentação liquida pastosa também pelo período de 30 dias para evitar que o enxerto e material de síntese se desloquem. O retorno para acompanhamento deve ser periódico para realização de exames físicos e analise radiográfica ${ }^{15}$.

No caso clínico relatado, o paciente retornou ao ambulatório com trismo e aumento de volume. Ao exame radiográfico observou-se que a placa e os parafusos do segmento proximal estavam deslocados. $\mathrm{O}$ paciente relatou ter cumprido pena em regime fechado após o procedimento cirúrgico. Diante da condição do paciente, a principal hipótese levantada foi que a complicação pós-operatória foi decorrente da negligência de cuidados no pós-operatório.

\section{CONCLUSÃO}

Cirurgias radicais geralmente acarretam aos pacientes sérias complicações. Entretanto, o ameloblastoma tem alta incidência de recidiva quando não removido adequadamente, tornando a ressecção cirúrgica do tumor, o tratamento de escolha para esse tipo de lesão.

\section{REFERÊNCIAS}

1. Agani Z, Hamiti-Krasniqi V, Recica J, Loxha MP, Kurshumliu F, Rexhepi A. Maxillary unicystic ameloblastoma: a case report. BMC research notes. 20169: 469.

2. Dandriyal R, Gupta A, Pant S, Baweja HH. Surgical management of ameloblastoma: Conservative or radical approach. Natl J Maxillofac Surg, 2011; 2(1):22-7.

3. Davanian H, Balasiddaiah A, Heymann R, Sundström M, Redenström P, Silfverberg M et al. Ameloblastoma RNA profiling uncovers a distinct non-coding RNA signature. Oncotarget. 2017; 8(3): 4530-42.

4. Martin Y, Sathyakumar M, Premkumar J, Magesh KT. Granular cell ameloblastoma. J Oral Maxillofac Pathol. 2017; 21(1):183.

5. Carvalho KM, Dhupar A, Spadigam A, Syed S. Ameloblastoma: A 16-year clinicopathological study on Goan population. Indian J Pathol Microbiol 2017; 60(2):157-60.

6. Bataineh $\mathrm{AB}$. Effect of preservation of the inferior and posterior borderson recurrence of ameloblastomas of the mandible. Oral Surg Oral Med Oral Pathol Oral Radiol Endod. 2000; 90(2):155-63.

7. Jain K, Sharma G, Kardam P, Mehendiratta M. Unicystic ameloblastoma of mandible with an unusual diverse histopathology: a rare case report. J Clin Diagn Res. 2017; 11(4): ZD04-05

8. Montoro JRMC, Tavares MG, Melo DH, Franco RL, Mello-Filho FV, Xavier SP et al. Ameloblastoma mandibular tratado por ressecção óssea e reconstrução imediata. Rev Bras Otorrinolaringol. 2008; 74(1):155-7.
9. Mendenhall WM, Werning JW, Fernandes RDMD, Malyapa RS, Mendenhall NP. Ameloblastoma. Am J Clin Oncol. 2007; 30(6):645-8.

10. Chapelle KA, Stoelinga PJ, de Wilde PC, Brouns JJ, Voorsmit RA. Rational approach to diagnosis and treatment of ameloblastomas and odontogenic keratocysts. Br J Oral Maxillofac Surg. 2004; 42(5): 381-90.

11. Hong J, Yun PY, Chung IH, Myoung H, Suh JD, Seo BM et al. Long-term follow up on recurrence of 305 ameloblastoma cases. Int J Oral Maxillofac Surg. 2007; 36(4):283-8.

12. Fardin AC, Jardim ECG, Pereira FC, Guskuma MH, Aranega AM, Garcia Junior IR. Bone graft in dentistry: review of literature. Innov. Implant. J. 2010; 5(3):48-52.

13. Valcania T, Panarello AF, Chaves-Júnio AC, Palma FR, Beltrão GC. Reconstrução de maxila utilizando enxerto ósseo da crista ilíaca. Rev Robrac. 2004; 13(36):20-4.

14. Mendonça JCG, Lima CMC, Terra GAP. Uso de enxerto ósseo autógeno de crista ilíaca na reconstrução de fenda alveolar em paciente fissurada: relato de caso. Rev Bras Cir Craniomaxilofac. 2011; 14(3):162-5.

15. Ribeiro Junior O, Gouveia MM, Alves CAF, Guimarães Junior J. Princípios da reconstrução mandibular com enxerto ósseo vascularizado. Rev Cir Traumatol BucoMaxilo-fac. 2008; 8(1):15-22.

\section{CONFLITO DE INTERESSES}

Os autores declaram não haver conflitos de interesse.

\section{AUTOR PARA CORRESPONDÊNCIA}

\section{Salmo Cortiglio}

scortiglio@gmail.com

Submetido em 20/02/2018 Aceito em 19/03/2018 